\title{
Serological relationships among genotypic variants of betanodavirus
}

\author{
K. Mori ${ }^{1}$, T. Mangyoku ${ }^{2}$, T. Iwamoto ${ }^{1}$, M. Arimoto ${ }^{1}$, S. Tanaka ${ }^{3}$, T. Nakai ${ }^{2, *}$ \\ ${ }^{1}$ Kamiura Station, Japan Sea-Farming Association, Oita 879-2602, Japan \\ ${ }^{2}$ Fish Pathobiology Laboratory, Graduate School of Biosphere Science, Hiroshima University, Higashihiroshima 738-8528, Japan \\ ${ }^{3}$ Owase Fisheries Laboratory, Fisheries Research Division, Mie Prefectural Science and Technology Promotion Center, \\ Owase, Mie 519-3602, Japan
}

\begin{abstract}
Betanodaviruses, the causative agents of viral nervous necrosis or viral encephalopathy and retinopathy, are divided into 4 genotypes based on the coat protein gene (RNA2). In the present study, serological relationships among betanodavirus genotypic variants were examined by virus neutralization tests using rabbit antisera raised against purified virions of strains representative of each genotype. All 20 isolates examined shared epitopes for neutralizing, but they fell into 3 major serotypes $(A, B, C)$. This sero-grouping is in part consistent with their genotypes, i.e. Serotype A for striped jack nervous necrosis virus (SJNNV) genotype, Serotype B for tiger puffer nervous necrosis virus (TPNNV) genotype, and Serotype $\mathrm{C}$ for both redspotted grouper nervous necrosis virus (RGNNV) and barfin flounder nervous necrosis virus (BFNNV) genotypes. The serological relatedness between RGNNV and BFNNV genotypes may result from their relatively higher similarity in RNA2 sequences. In neutralization tests using antisera of kelp grouper Epinephelus moara, which were raised against recombinant coat proteins representing each genotype, anti-SJNNV and antiTPNNV sera neutralized only the homologous strain, and anti-RGNNV and anti-BFNNV sera reacted with both RGNNV and BFNNV strains. The present serological findings will be important in investigating the infectivity and host-specificity of betanodaviruses and in developing vaccines for the disease.
\end{abstract}

KEY WORDS: Betanodavirus · Viral nervous necrosis · Viral encephalopathy · Viral retinopathy · Serotyping $\cdot$ Virus neutralization $\cdot$ Recombinant protein

\section{INTRODUCTION}

Betanodaviruses (genus Betanodavirus, Nodaviridae) have a variety of cultured fish species as natural hosts, and cause viral nervous necrosis (VNN) or viral encephalopathy and retinopathy (VER) (Office International des Epizooties 2000, Munday et al. 2002). The genome of the betanodaviruses consists of 2 single-stranded, positive-sense RNAs. RNA1 (3.1 kb) encodes the viral replicase, and RNA2 (1.4 kb) encodes the capsid protein. Based on the sequence of part of the coat protein gene, betanodaviruses are currently grouped into 4 genotypes (Nishizawa et al. 1997): SJNNV (striped jack nervous necrosis virus, the type species of the genus Betanodavirus), TPNNV (tiger puffer nervous necrosis virus), RGNNV (redspotted grouper nervous necrosis virus), and BFNNV (barfin flounder nervous necrosis virus) types. Complete nucleotide sequences of RNA1 and RNA2 of SJNNV and GGNNV (a grouper betanodavirus belonging to RGNNV genotype) have been reported (Iwamoto et al. 2001, Tan et al. 2001).

The host fish of the SJNNV and TPNNV genotypes has been limited to striped jack Pseudocaranx dentex (Mori et al. 1992) and tiger puffer Takifugu rublipes (Nakai et al. 1994), respectively. In contrast, the RGNNV genotype has been isolated from a wide range of warm-water marine fish species, such as groupers and sea bass (Glazebrook et al. 1990, Danayadol et al. 1995, Chi et al. 1997, Le Breton et al. 1997, Skliris et al. 2001), and the freshwater guppy Poicelia reticulata 
(Hegde et al. 2003), while the BFNNV genotype has been isolated from cold-water species such as turbot Scophthalmus maximus, Atlantic halibut Hippoglossus hippoglossus, and barfin flounder Verasper moseri (Bloch et al. 1991, Grotmol et al. 1997, Watanabe et al. 1999). An experiment with cultured cells revealed different optimal growth temperatures for these genotypic variants: 25 to $30^{\circ} \mathrm{C}$ for RGNNV, 20 to $25^{\circ} \mathrm{C}$ for SJNNV, $20^{\circ} \mathrm{C}$ for TPNNV, and 15 to $20^{\circ} \mathrm{C}$ for BFNNV (Iwamoto et al. 2000). Some infection experiments support the possibility that each genotypic variant of betanodaviruses is different in pathogenicity (Iwamoto et al. 1999, Totland et al. 1999, Skliris et al. 2001). Thus, it is likely that these genetic variants have their own host-specificity, pathogenicity and ecology. However, genetic and phenotypic information on betanodaviruses is still limited. In the present study, betanodavirus isolates belonging to different genotypes were compared serologically by virus neutralization and fluorescent antibody tests using rabbit and fish polyclonal antibodies.

\section{MATERIALS AND METHODS}

Virus isolates. We used 4 strains of betanodavirus belonging to different genotypes as immunogens for antiserum production in rabbit and fish: SJNag93 (SJNNV genotype), TPKag93 (TPNNV genotype), SGWak97 (RGNNV genotype), and JFIwa98 (BFNNV genotype), which had been isolated from striped jack Pseudocaranx dentex, tiger puffer Takifugu rubripes, sevenband grouper Epinephelus septemfasciatus, and Japanese flounder Paralichthys olivaceus, respectively (Iwamoto et al. 1999). We used 16 other betanodavirus isolates from diseased fishes in neutralization tests with the antisera (see Table 1). These, except JFHir96, were used in our previous studies (Iwamoto et al. 1999, Curtis et al. 2001, Tanaka et al. 2001, Yuasa et al. 2002). Fish-pathogenic infectious pancreatic necrosis virus (IPNV; VR299 strain), infectious hematopoietic necrosis virus (IHNV; ChAb strain) and viral hemorrhagic septicemia virus (VHSV; Obama25 strain) were also used as reference viruses for neutralization tests.

Sequence analysis. The T4 regions (nucleotide position [nt] 624 to 1010 or amino acid position [aa] 204 to 331 in Nishizawa et al. 1995) in the coat protein gene were sequenced for comparison of the isolates. Extraction of total RNA and reverse transcription (RT)-PCR amplification of the viral gene were performed as previously described (Nishizawa et al. 1995, Iwamoto et al. 2001). Primers were F2 (5'-CGTGTCAGTCATGTGTCGCT-3') and R3 (5'-CGAGTCAACACGGGTGAAGA-3'). The PCR products were purified from Tris-borate-EDTA NuSieve 3:1 agarose gels (Bio Whit- taker Molecular Applications) with a Quantum Prep ${ }^{\mathrm{TM}}$ gel-extraction spin-columns kit (Bio-Rad Laboratories) to determine the nucleotide sequence with a dye-terminator cycle-sequencing kit (Applied Biosystems) and the Auto Sequencer Model 377 (Applied Biosystems). Multiple alignments of determined nucleotide and deduced amino acid sequences were constructed with the Genetyx program version 6.1.0 (Software Development). A molecular phylogenetic tree of the nucleotide sequences of isolates was built by the maximum likelihood criteria with the Dnaml program of PHYLIP 3.573c (Felsenstein 1993).

Virus purification. E-11 cells (Iwamoto et al. 2000) were cultured in a $150 \mathrm{~cm}^{2}$ tissue culture flask (Sumitomo Bakelite) at $25^{\circ} \mathrm{C}$ for $24 \mathrm{~h}$ using Leibovitz L-15 medium (Gibco BRL) supplemented with $5 \%$ fetal bovine serum (FBS). The monolayer was washed twice with Hanks' balanced salt solution (HBSS), and $100 \mu \mathrm{l}$ of the respective virus isolate (SJNag93, TPKag93, SGWak97, JFIwa98) was then inoculated into the cell culture (multiplicity of infection $=1$ ). After standing at $25^{\circ} \mathrm{C}$ for $1 \mathrm{~h}$, the flask was washed with HBSS and supplemented with L-15 medium ( $2 \%$ FBS). Cells were incubated at $25^{\circ} \mathrm{C}$ for SJNag93 and SGWak97 or $20^{\circ} \mathrm{C}$ for TPKag93 and JFIwa98 until the cell sheet completely disintegrated after exhibition of characteristic cytopathic effects (CPE) (5 to $7 \mathrm{~d}$ incubation). The culture fluids were centrifuged at $8000 \times g$ for $20 \mathrm{~min}$. The sediments were vigorously vortexed with TET buffer (100 mM Tris $\mathrm{HCl}, 1$ mM EDTA, pH 7.2, 0.1\% Triton $\mathrm{X}-100)$ and centrifuged $(8000 \times g, 20 \mathrm{~min})$. Both supernatants were mixed, centrifuged at $100000 \times g$ for $3 \mathrm{~h}$ (Hitachi P70AT rotor), and TET buffer was added to the sediments. After incubation at $4^{\circ} \mathrm{C}$ overnight and centrifugation $(12000 \times g, 15 \mathrm{~min})$, the supernatant was mixed with $\mathrm{CsCl}$ (adjusted to $36 \%[\mathrm{w} / \mathrm{v}$ ] in final concentration) and centrifuged at $157000 \times g$ for $20 \mathrm{~h}$ $\left(16^{\circ} \mathrm{C}\right)$ in a Hitachi P55ST2 rotor. The virus band obtained $(1 \mathrm{ml})$ was dialysed against TE buffer $(100 \mathrm{mM}$ Tris $\mathrm{HCl}_{1} 1$ mM EDTA, pH 7.2) overnight. Approximately $0.1 \mathrm{mg}$ of virus, which was estimated from the RNA content, was purified from each $150 \mathrm{~cm}^{2}$ culture. The genotypes of the purified viruses were checked again by nested PCR using genotype-specific primers (data not shown).

Recombinant protein preparation. Recombinant coat proteins of the virus isolates (SJNag93, TPKag93, SGWak97, JFIwa98) were expressed in Escherichia coli as described previously (Tanaka et al. 2001). Briefly, the sense primer 5'-gactccATGGTACGCAAAGGTGA$3^{\prime}$ and antisense primer $5^{\prime}$-cagctcgaGGCCATTTAACCACATG-3' for SJNag93, TPKag93, SGWak97, or 5'-caggatccGGCCATTTAACCACATG-3' for JFIwa98 (lowercase letters $=$ linker sequences) were used for amplification of a target region containing the open 
reading frame. The PCR amplicons were digested with $\mathrm{NCOI}$ and XhoI restriction enzymes and ligated in a pET-16b plasmid (Novagen). E. coli BL21(DE3) (Novagen) was used as an expression host. The recombinant E. coli was cultured in LB midium supplemented with ampicillin at $37^{\circ} \mathrm{C}$. After induction by isopropyl-thio- $\beta$-D-galactoside, the culture was centrifuged at $3000 \times g$ for $20 \mathrm{~min}$ and the cells were sonicated. The virus coat protein, obtained as insoluble fraction, was analyzed by $12.5 \%$ SDS-polyacrylamide gel (PAGE) and Western blot using the rabbit antibetanodavirus serum (100-fold diluted) described below. The insoluble fraction was suspended in phosphate-buffered saline $\left(1 \mathrm{mg}\right.$ protein $\left.\mathrm{ml}^{-1}\right)$ and used as an immunogen for the fishes. The protein content of the fraction was estimated optically after treated with $8 \mathrm{M}$ urea.

Antisera production. Purified virus $(25 \mu \mathrm{g})$ was emulsified with Freund's complete adjuvant (FCA) and injected subcutaneously into rabbits. Booster injections of virus without FCA were given several times intravenously until neutralization titers against homologous virus reached 10000 or higher. For antisera production in fishes, kelp grouper Epinephelus moara weighing on average $70 \mathrm{~g}$ were immunized with the recombinant virus coat proteins; 10 fish per each protein were given 2 intraperitoneal injections with FCA-emulsified protein $\left(500 \mu \mathrm{g} \mathrm{fish}^{-1}\right)$ at $10 \mathrm{~d}$ intervals, and subsequent 2 intramuscular injections without FCA at $10 \mathrm{~d}$ intervals. Water temperature was kept at $28^{\circ} \mathrm{C}$ throughout the immunization period, and $10 \mathrm{~d}$ after the last injection, the fish were bled and the serum in groups of 5 fish was pooled. The rabbit and fish antisera were sterilized through $0.45 \mu \mathrm{m}$ membrane filters and stored at $-80^{\circ} \mathrm{C}$.

Virus neutralization test. E-11 cells were cultured in 96-well tissue culture plates (Corning) supplemented with L-15 medium (5\% FBS). The antiserum was serially diluted 2-fold (1:20 to 1:81920) with HBSS, and then mixed with an equal volume of the virus $\left(10^{1.5}\right.$ to $10^{2.0} \mathrm{TCID}_{50} 0.025 \mathrm{ml}^{-1}$ ). After incubation for $1 \mathrm{~h}$, the mixture was inoculated into the wells; 4 wells were used for each diluted sample. Cytopathic effects (CPE) were observed at $25^{\circ} \mathrm{C}$ (SJNNV and RGNNV genotypes) or $20^{\circ} \mathrm{C}$ (TPNNV and BFNNV genotypes) for $10 \mathrm{~d}$, and the virus-neutralizing titer of serum was shown as a reciprocal of the highest dilution of serum that completely inhibited CPE. The serological relationships among betanodavirus isolates were compared using the value of $1 / \mathrm{r}$ from the formula: $r=\sqrt{r 1 \times r 2}$, where $\mathrm{r} 1$ and $\mathrm{r} 2$ are the titer-ratios (heterologous titer divided by homologous titer for the respective antisera) (Archetti \& Horsfall 1950).

Indirect fluorescent antibody test (IFAT). We subjected 4 virus isolates used for production of rabbit antiserum to IFAT. $100 \mu \mathrm{l}$ of the virus solution $\left(10^{6}\right.$ $\mathrm{TCID}_{50} \mathrm{ml}^{-1}$ ) was inoculated into a $0.8 \mathrm{~cm}^{2}$ chamber of a Lab-Tek chamber slide (Nunc) which contained a semi-confluent layer of cells. After incubation at 25 or $20^{\circ} \mathrm{C}$ for $3 \mathrm{~d}$, cells were fixed with methanol and immunostained. Cells in the chamber were incubated with serially 2 -fold-diluted (1:100 to 1:3200) rabbit antiserum and then reacted with fluorescein isothiocyanate (FITC)-conjugated swine anti-rabbit immunoglobulin (Dako) as described previously (Iwamoto et al. 1999). The intensity of the fluorescence signals is given as a roughly estimated number of positive cells $\left(+=\right.$ fewer than $100 ;++=100$ to $1000_{i}+++=$ more than 1000 in a chamber).

\section{RESULTS}

\section{Nucleotide and amino acid sequence similarities}

The lengths of amplified PCR products of the T4 region in the coat protein gene were the same in isolates SJNag91, SJNag92, SJNag93, and TPKag93, while the other 16 isolates lacked 6 bases at positions corresponding to nt 724 to 729 , as previously reported (Nishizawa et al. 1997). Based on a molecular phylogenetic tree deduced from multiple alignment of the nucleotide sequences (data not shown), the isolates of betanodavirus were classified into 1 of 4 clusters, SJNNV, TPNNV, RGNNV and BFNNV, as shown in Table 1. Deduced amino acid sequences (aa 204 to 331 in Nishizawa et al. 1995) of the T4 region are shown in Fig. 1, and amino acid sequence similarities are shown in Table 2 . The sequence similarities among genotypes were high: $\geq 99.2 \%$ identity among the 3 isolates of the SJNNV genotype, $\geq 92.9 \%$ among the 13 isolates of the RGNNV genotype, and 100\% among the 3 isolates of the BFNNV genotype. Sequence identities between isolates of different genotypes were $75.0 \%$ or lower, except for relatively higher identities between isolates of the RGNNV and BFNNV genotypes ( 83.3 to $85.7 \%)$.

\section{Neutralization test with rabbit antisera}

Homologous neutralizing titers of rabbit antisera raised against purified SJNag93, TPKag93, SGWak97 and JFIwa98 were 40 960, 10 240, 20480 and 20 480, respectively (Table 1). The neutralizing activity of these rabbit antisera was highly specific to betanodaviruses, and the titers were 20 or lower against 3 other fish pathogenic viruses (IPN, IHN, VHS). The anti-SJNag93 serum exhibited a similar titer against the other 2 virus isolates from striped jack. Both anti-SGWak97 and anti- 
Table 1. Virus strains used and neutralizing antibody titers of 4 rabbit antisera raised against different genotypes of betanodavirus. IPNV: infectious pancreatic necrosis virus; IHNV: infectious hematopoietic necrosis virus; VHSV: viral hemorrhagic septicemia virus. Sources: (1) Iwamoto et al. (1999), (2) Tanaka et al. (2001), (3) Yuasa et al. (2002), (4) Curtis et al. (2001), (5) present study

\begin{tabular}{|c|c|c|c|c|c|c|c|c|}
\hline $\begin{array}{l}\text { Virus } \\
\text { Strain (Source) }\end{array}$ & Host fish & Location & Genotype & $\begin{array}{c}\text { Neutralizin } \\
\text { SJNag93 }\end{array}$ & $\begin{array}{l}9 \text { titers of a } \\
\text { TPKag93 }\end{array}$ & $\begin{array}{l}\text { tiserum rais } \\
\text { SGWak97 }\end{array}$ & $\begin{array}{l}\text { sed against } \\
\text { JFIwa98 }\end{array}$ & Serotype \\
\hline \multicolumn{9}{|l|}{ Betanodavirus } \\
\hline SJNag91 (1) & Striped jack (Pseudocaranx dentex) & Japan & SJNNV & 20480 & 160 & 320 & 640 & $\mathrm{~A}$ \\
\hline SJNag92 (1) & Striped jack & Japan & SJNNV & 20480 & 320 & 320 & 320 & $\mathrm{~A}$ \\
\hline SJNag93 (1) & Striped jack & Japan & SJNNV & 40960 & 640 & 160 & 320 & $\mathrm{~A}$ \\
\hline TPKag93 (1) & Tiger puffer (Takifugu rublipes) & Japan & TPNNV & 640 & 10240 & 640 & 1280 & $\mathrm{~B}$ \\
\hline \multirow[t]{2}{*}{ SGWak97 (1) } & Sevenband grouper & & & & & & & \\
\hline & (Epinephelus septemfasciatus) & Japan & RGNNV & 160 & 160 & 20480 & 20480 & $\mathrm{C}$ \\
\hline SGMie95 (2) & Sevenband grouper & Japan & RGNNV & 320 & 320 & 20480 & 20480 & $\mathrm{C}$ \\
\hline RGOka94 (1) & Redspotted grouper (E. akaara) & Japan & RGNNV & 640 & 320 & 40960 & 20480 & $\mathrm{C}$ \\
\hline JSOit98 (1) & Japanese sea bass (Lateolabrax japonicus) & Japan & RGNNV & 640 & 80 & 40960 & 20480 & $\mathrm{C}$ \\
\hline KGOit97 (1) & Kelp grouper (E. moara) & Japan & RGNNV & 320 & 160 & 20480 & 40960 & $\mathrm{C}$ \\
\hline HG0001 (3) & Humpback grouper (Cromileptes altivelis) & Indonesia & RGNNV & 640 & 640 & 40960 & 20480 & $\mathrm{C}$ \\
\hline BGTha99 (1) & Brownspotted grouper (E. coioides) & Thailand & RGNNV & 80 & 160 & 20480 & 40960 & $\mathrm{C}$ \\
\hline SBGre96 (1) & European sea bass (Dicentrarchus labrax) & Greece & RGNNV & 320 & 80 & 40960 & 81920 & $\mathrm{C}$ \\
\hline WSBUS99A (4) & White sea bass (Atractoscion nobilis) & USA & RGNNV & 640 & 80 & 20480 & 20480 & $\mathrm{C}$ \\
\hline WSBUS99B (4) & White sea bass & USA & RGNNV & 1280 & 80 & 81920 & 81920 & $\mathrm{C}$ \\
\hline BAAus94 (1) & Barramundi (Lates calcarifer) & Australia & RGNNV & 320 & 80 & 40960 & 81920 & $\mathrm{C}$ \\
\hline JFHir92 (1) & Japanese flounder (Paralichthys olivaceus) & Japan & RGNNV & 1280 & 40 & 40960 & 40960 & $\mathrm{C}$ \\
\hline JFHir96 (5) & Japanese flounder & Japan & RGNNV & 80 & 80 & 81920 & 20480 & $\mathrm{C}$ \\
\hline JFIwa96 (1) & Japanese flounder & Japan & BFNNV & 2560 & 80 & 81920 & 81920 & $\mathrm{C}$ \\
\hline JFIwa98 (1) & Japanese flounder & Japan & BFNNV & 1280 & 640 & 10240 & 20480 & $\mathrm{C}$ \\
\hline PCHok96 (1) & Pacific cod (Gadus macrocephalus) & Japan & BFNNV & 160 & 320 & 20480 & 40960 & $\mathrm{C}$ \\
\hline IPNV VR299 & & & & $<20$ & $<20$ & $<20$ & $<20$ & \\
\hline IHNV ChAb & & & & $<20$ & $<20$ & $<20$ & $<20$ & \\
\hline VHSV Obama25 & & & & $<20$ & $<20$ & $<20$ & $<20$ & \\
\hline
\end{tabular}

Table 2. Amino acid sequence identities of coat protein (T4 region: aa 204 to 331) of 20 betanodavirus strains

\begin{tabular}{|c|c|c|c|c|c|c|c|c|c|c|c|c|}
\hline $\begin{array}{l}\text { Virus strain } \\
\text { (genotype) }\end{array}$ & $\begin{array}{l}\text { SJNag91 } \\
\text { SJNag92 } \\
\text { (SJNNV) }\end{array}$ & $\begin{array}{l}\text { SJNag93 } \\
\text { (SJNNV) }\end{array}$ & $\begin{array}{l}\text { TPKag93 } \\
\text { (TPNNV) }\end{array}$ & $\begin{array}{c}\text { JFIwa96 } \\
\text { JFIwa98 } \\
\text { PCHok96 } \\
\text { (BFNNV) }\end{array}$ & $\begin{array}{c}\text { BGTha99 } \\
\text { BaAus94 } \\
\text { HG0001 } \\
\text { RGOka94 } \\
\text { (RGNNV) }\end{array}$ & $\begin{array}{c}\text { JFHir92 } \\
\text { JFHir96 } \\
\text { (RGNNV) }\end{array}$ & $\begin{array}{l}\text { JSOit98 } \\
\text { (RGNNV) }\end{array}$ & $\begin{array}{l}\text { KGNag97 } \\
\text { SGWak97 } \\
\text { (RGNNV) }\end{array}$ & $\begin{array}{l}\text { SBGre96 } \\
\text { (RGNNV) }\end{array}$ & $\begin{array}{l}\text { SGMie95 } \\
\text { (RGNNV) }\end{array}$ & $\begin{array}{l}\text { WSBUS99A } \\
\text { (RGNNV) }\end{array}$ & $\begin{array}{c}\text { WSBUS99B } \\
\text { (RGNNV) }\end{array}$ \\
\hline SJNag91/ SJNag92 & ${ }^{*}$ & & & & & & & & & & & \\
\hline SJNag93 & 99.2 & $*$ & & & & & & & & & & \\
\hline TPKag93 & 75.0 & 74.2 & * & & & & & & & & & \\
\hline JFIwa96/JFIwa98/ & & & & & & & & & & & & \\
\hline $\begin{array}{l}\text { PCHok96 } \\
\text { BGTha99/BaAus94/ }\end{array}$ & 70.3 & 69.5 & 75.0 & * & & & & & & & & \\
\hline HG0001/RGOka94 & 70.3 & 69.5 & 72.7 & 85.7 & $*$ & & & & & & & \\
\hline JFHir92/JFHir96 & 71.1 & 70.3 & 72.7 & 85.7 & 96.8 & * & & & & & & \\
\hline JSOit98 & 69.5 & 68.8 & 71.9 & 84.1 & 98.4 & 95.2 & * & & & & & \\
\hline KGNag97/SGWak97 & 69.5 & 68.8 & 71.9 & 84.9 & 99.2 & 96.0 & 99.2 & * & & & & \\
\hline SBGre96 & 69.5 & 68.8 & 71.9 & 85.7 & 99.2 & 96.0 & 97.6 & 98.4 & $*$ & & & \\
\hline SGMie95 & 69.5 & 68.8 & 72.9 & 85.7 & 99.2 & 96.0 & 97.6 & 98.4 & 98.4 & $*$ & & \\
\hline WSBUS99A & 69.5 & 68.8 & 71.1 & 83.3 & 95.2 & 93.7 & 95.2 & 94.4 & 94.4 & 94.4 & * & \\
\hline WGBUS99B & 69.5 & 68.0 & 71.1 & 83.3 & 94.4 & 92.9 & 94.4 & 93.7 & 93.7 & 94.4 & 99.2 & $*$ \\
\hline
\end{tabular}

JFIwa98 sera exhibited 10240 or higher titers against the 13 isolates of the RGNNV genotype and the 3 isolates of the BFNNV genotype. Heterologous titers were reduced 10 times or more compared to the homologous titers, except for titers of anti-SGWak97 against the
BFNNV genotype or titers of anti-JFIwa98 against the RGNNV genotype. Serological relationships among the 4 strains used to generate antibodies are shown in Table 3 as 1/r values; larger values indicate greater serological differences between the strains. 
Table 3. Serological relationship (1/r) between 4 genotypic variants of betanodavirus. $1 / \mathrm{r}$ value: $\mathrm{r}=\sqrt{\mathrm{r} 1 \times \mathrm{r} 2}$, where $\mathrm{r} 1$ and r2 are titer ratios (heterologous titer divided by homologous titer for respective antisera)

\begin{tabular}{|lcrrr|}
\hline $\begin{array}{l}\text { Antiserum } \\
\text { against }\end{array}$ & $\begin{array}{c}\text { Virus strain (genotype) } \\
\text { SJNag93 } \\
\text { (SJNNV) }\end{array}$ & $\begin{array}{l}\text { TPKag9 } \\
\text { (TPNNV) }\end{array}$ & $\begin{array}{c}\text { SGWak97 } \\
\text { (RGNNV) }\end{array}$ & $\begin{array}{c}\text { JFIwa98 } \\
\text { (BFNNV) }\end{array}$ \\
\hline SJNag93 & \multirow{2}{*}{1.0} & 32.0 & 181.1 & 45.3 \\
TPKag93 & & 1.0 & 45.3 & 16.0 \\
SGWak97 & & & 1.0 & 1.4 \\
JFIwa98 & & & & 1.0 \\
\hline
\end{tabular}

\section{IFAT with rabbit antisera}

In IFAT, every isolate reacted positively with all 4 rabbit antisera at 1:200 dilution (Table 4). Isolates were highly reactive to the homologous antiserum, and positive fluorescence was observed until an 800-fold or 1600 -fold dilution of the serum.

\section{Neutralization test with fish antisera}

All 4 recombinant coat proteins constructed from SJNag93, TPKag93, SGWak97 and JFIwa98 isolates

SJNag91
SJNag92
SJNag93
TPKag93
JFIwa96
JFIwa98
PCHok96
BGTha99
BaAus94
HG0001
JFHir92
JFHir96
JSOit98
KGNag97
RGOka94
SBGre96
SGMie95
SGWak97
WSBUS99A
WSBUS99B

204 SVRLSVPSLETPEDTTAPITTQAPLHNDSINNGYTGFRSILLGSTQLDLAPANAVFVTDKPLPIDYNLGV

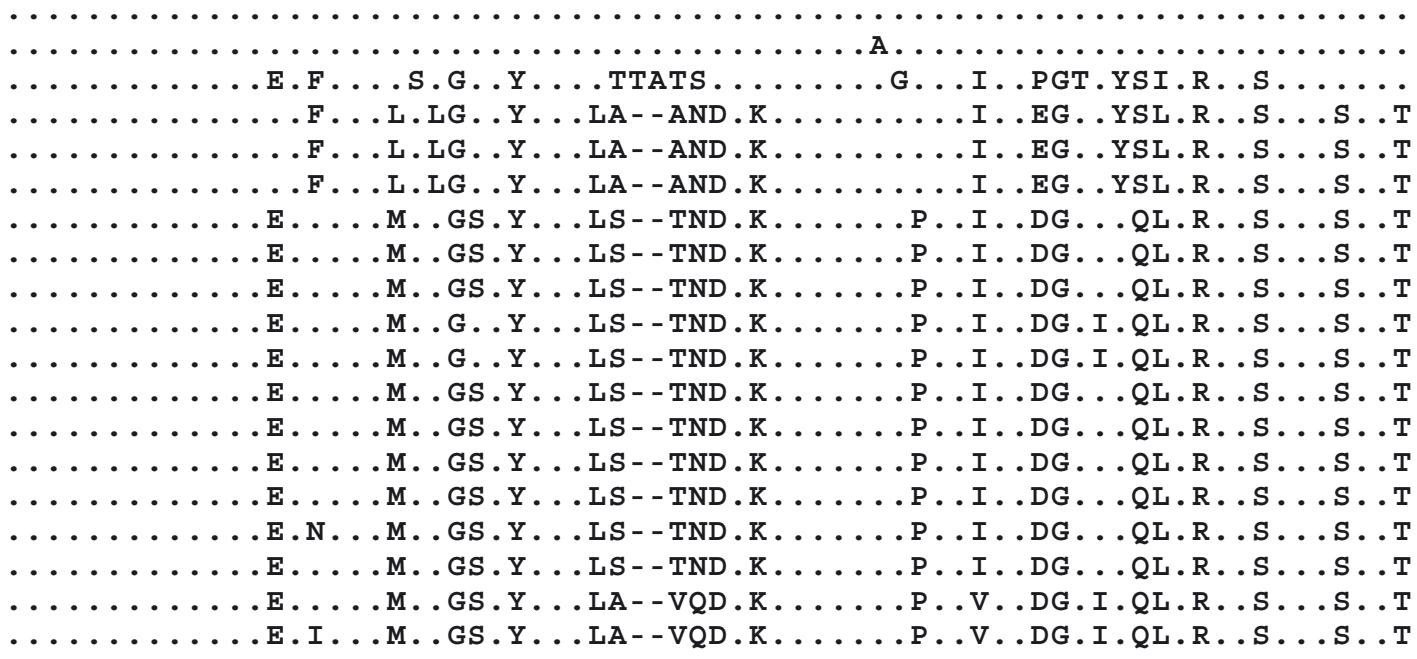

Fig. 1. Multiple alignment of deduced amino acid sequences of 20 betanodavirus strains in T4 region (aa 204-331) of the coat protein. Dot: amino acid residue identical to that at same position in reference sequence of SJNag91; hyphen: amino acid gap inserted 
Table 4. Indirect fluorescent antibody tests with rabbit antisera and 4 genotypic variants of betanodavirus. Intensity of fluorescence signals given as roughly estimated number of positive cells (-: zero, $+:<100,++: 100$ to 1000, +++ : $>1000$ positive cells $0.8 \mathrm{~cm}^{-2}$ )

\begin{tabular}{|lllllllll|}
\hline \multirow{2}{*}{$\begin{array}{l}\text { Virus strain } \\
\text { (genotype) }\end{array}$} & Antiserum & \multicolumn{7}{c|}{ Dilution of antiserum } \\
& against & $\times 100$ & $\times 200$ & $\times 400$ & $\times 800$ & $\times 1600$ & $\times 3200$ \\
\hline SJNag93 & SJNag93 & +++ & +++ & ++ & + & + & - \\
(SJNNV) & TPKag93 & ++ & ++ & + & - & - & - \\
& SGWak97 & +++ & ++ & + & + & - & - \\
& JFIwa98 & +++ & ++ & + & - & - & - \\
TPKag93 & SJNag93 & ++ & ++ & + & - & - & - \\
(TPNNV) & TPKag93 & +++ & +++ & ++ & ++ & + & - \\
& SGWak97 & ++ & + & + & - & - & - \\
& JFIwa98 & ++ & ++ & ++ & + & - & - \\
SGWak97 & SJNag93 & ++ & + & + & + & - & - \\
(RGNNV) & TPKag93 & ++ & + & - & - & - & - \\
& SGWak97 & +++ & +++ & ++ & + & + & - \\
& JFIwa98 & ++ & ++ & ++ & + & + & - \\
JFIwa98 & SJNag93 & ++ & ++ & + & - & - & - \\
$($ BFNNV) & TPKag93 & ++ & + & + & - & - & - \\
& SGWak97 & +++ & ++ & ++ & ++ & + & - \\
& JFIwa98 & +++ & ++ & + & + & - & - \\
& & & + & & & & & \\
\hline
\end{tabular}

\section{DISCUSSION}

In previous reports, immunostaining of infected fish sections or cultured cells with polyclonal antibodies indicated the presence of common antigen(s) among all betanodaviruses, irrespective of genetic variations or geographically and chronologically different virus sources (Munday et al. 1994, Grotmol et al. 1997, Iwamoto et al. 1999). However, it was noticed empirically that the intensity of antibody reaction in FAT or immunoblots varied among genotypes, and only a few papers described serological differences among different isolates of betanodavirus. In a qualitative cross-neutralizing test with rabbit antisera, Skliris et al. (2001) reported that Greek and Maltese isolates (RGNNV genotype) from European sea bass Dicentrarchus labrax were serologically different from SJNNV (a Japanese isolate from striped jack). Another report, in which different genotypes were ana-

had a similar (approximately $42 \mathrm{kDa}$ ) molecular weight in SDS-PAGE (Fig. 2A) and reacted with any of the rabbit antisera in Western blot analysis, although there were slight differences in the reactivity (Fig. 2B). The neutralizing titers of the antirecombinant proteins raised in kelp grouper are shown in Table 5. There were no significant differences between the 2 pools in the neutralizing titers. SJNag93 and TPKag93 strains were neutralized only by the anti-SJNag93 and anti-TPKag93 serum, respectively, while SGWak97 and JFIwa98 strains were neutralized by both anti-SGWak97 and anti-JFIwa98 sera. lyzed by Western blot using monoclonal antibodies against SJNNV, indicated that SJNNV could be distinguished serologically from the other genotypes of betanodaviruses (Nishizawa et al. 1999).

The present study clearly revealed serological relationships among the genotypes. Neutralization assays and IFAT demonstrated that all the isolates share one or more epitopes or antigens, but differences in neutralizing titers of the antisera indicate that betanodaviruses can be grouped into 3 distinct serotypes. As a parameter for serological difference, $1 / \mathrm{r}$ values were calculated from the homologous and heterologous neutralizing titers (Table 3 ). A $1 / \mathrm{r}$ value of 20 or
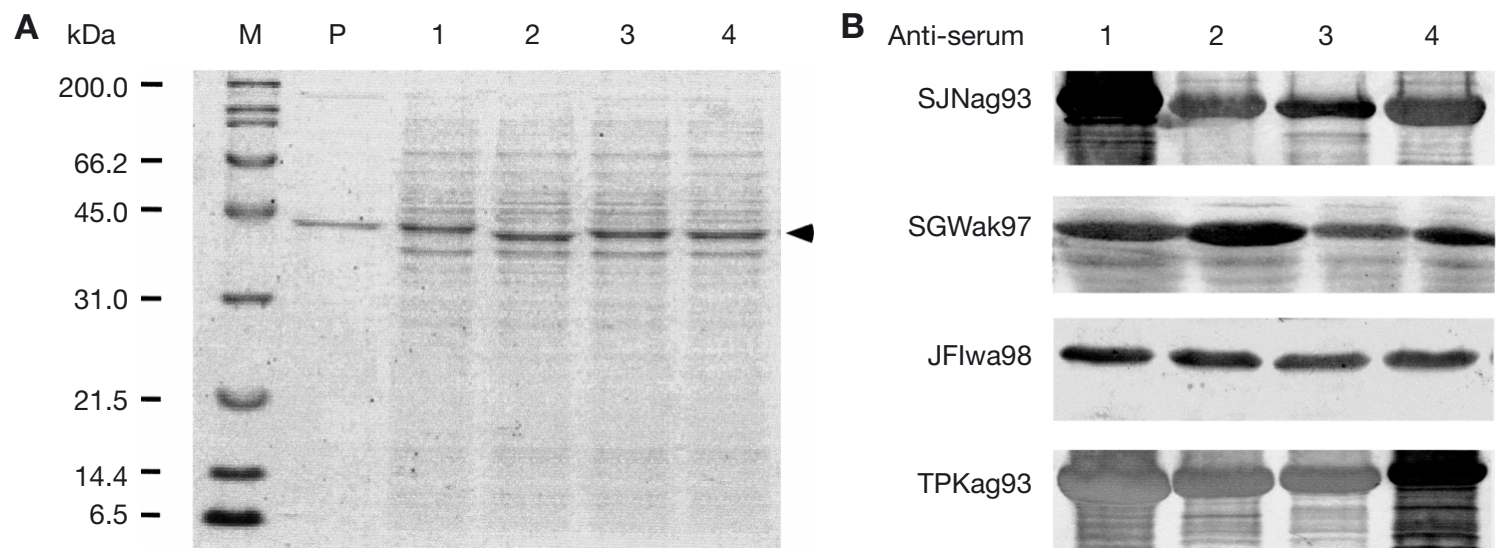

Fig. 2. (A) SDS-PAGE and (B) Western blot analyses of recombinant coat proteins constructed from 4 betanodaviruses. Lane M: marker DNA; Lane P: purified SJNNV; Lane 1: SJNag93 (SJNNV genotype); Lane 2: SGWak97 (RGNNV genotype); Lane 3: JFIwa98 (BFNNV genotype); Lane 4: TPKag93 (TPNNV genotype); arrowhead indicates recombinant coat proteins 
Table 5. Neutralizing antibody titers of fish antisera against 4 genotypic variants of betanodavirus

\begin{tabular}{|c|c|c|c|c|}
\hline \multirow{2}{*}{$\begin{array}{l}\text { Antiserum against } \\
\text { Serum pool no. }\end{array}$} & \multicolumn{4}{|c|}{ Neutralizing antibody titer of antiserum against } \\
\hline & $\begin{array}{l}\text { SJNag93 } \\
\text { (SJNNV) }\end{array}$ & $\begin{array}{l}\text { TPKag93 } \\
\text { (TPNNV) }\end{array}$ & $\begin{array}{l}\text { SGWak97 } \\
\text { (RGNNV) }\end{array}$ & $\begin{array}{l}\text { JFIwa98 } \\
\text { (BFNNV) }\end{array}$ \\
\hline \multicolumn{5}{|l|}{ SJNag93 } \\
\hline 1 & 1280 & $<40$ & $<40$ & $<40$ \\
\hline 2 & 2560 & $<40$ & $<40$ & $<40$ \\
\hline \multicolumn{5}{|l|}{ TPKag93 } \\
\hline 1 & $<40$ & 2560 & $<40$ & $<40$ \\
\hline 2 & $<40$ & 1280 & $<40$ & $<40$ \\
\hline \multicolumn{5}{|l|}{ SGWak97 } \\
\hline 1 & $<40$ & $<40$ & 5120 & 1280 \\
\hline 2 & $<40$ & $<40$ & 1280 & 1280 \\
\hline \multicolumn{5}{|l|}{ JFIwa98 } \\
\hline 1 & $<40$ & $<40$ & 5120 & 2560 \\
\hline 2 & $<40$ & $<40$ & 2560 & 1280 \\
\hline \multicolumn{5}{|l|}{ Control } \\
\hline 1 & $<40$ & $<40$ & $<40$ & $<40$ \\
\hline 2 & $<40$ & $<40$ & $<40$ & $<40$ \\
\hline
\end{tabular}

epitope, and that the sequences at the same position of TPNNV, RGNNV and BFNNV, i.e. PPG, PDG and PEG, respectively, are genotype-specific neutralizing epitopes of the betanodavirus. However, judging from the serological relatedness between the RGNNV and BFNNV genotypes, PDG and PEG are not candidates for epitopes specific to RGNNV and BFNNV. Sequences around L at aa 233 and 261, D at aa 239, K at aa 241 and 285, S at aa 270, T at aa 273, N at aa 290 and 305, and $W$ at aa 297 may be candidates for the neutralizing epitope of these genotypes, since they are commonly present in RGNNV and BFNNV genotypes but not in SJNNV or TPNNV genotypes. However, the surface sites on the betanodavirus predicted by the method of Emini et al. (1985) do not necessarily support this speculation (data not shown).

higher indicates that 2 viruses belong to serologically distinct groups (Jørgensen 1972). Based on this criterion, but with the 1 exception of $1 / \mathrm{r}=16.0$ between TPKag93 (TPNNV) and JFIwa98 (BFNNV), SJNNV genotype and TPNNV genotype are in Serotype A and Serotype B, respectively, and RGNNV and BFNNV genotypes are both grouped into Serotype C. The close serological relatedness $(1 / \mathrm{r}=1.4)$ between RGNNV and BFNNV genotypes contradicts our previous understanding that these genotypes apparently differ in their natural host species: warm-water fish for RGNNV and cold-water fish for BFNNV (see 'Introduction'). The presence of common neutralizing epitopes between these genotypes may be due to the distinctly higher sequence similarity in the coat protein (Table 2), although further study is required to determine details.

Identification of neutralizing epitopes of the virus is a step to finding factors associated with its infectivity. Recently, in a 3-dimensional reconstruction of virus structure based on electron cryomicroscopy, Tang et al. (2002) suggested that amino acid residues aa 217 to 308 of the coat protein form the trimeric surface protrusions of a betanodavirus (RGNNV genotype) isolated from the malabaricus grouper Epinephelus malabaricus. This region corresponds to the T4 region, which has proven to be variable in nucleotide sequences among betanodaviruses (Nishizawa et al. 1995, 1997). Nishizawa et al. (1999) have shown the existence of 2 PAN motifs (aa 116 to 118 and 254 to 256 ) in the T4 region of the SJNNV genotype, and have suggested that the PAN sequence located at aa 254 to 256 is most probably the major neutralizing
We recently succeeded in developing an infectious RNA transcription system for RGNNV, following establishment of the system for SJNNV (Iwamoto et al. 2001). This reverse genetics system will allow experiments using reassortants between 2 viruses and sitedirected mutations, and it will be of great value in identifying epitopes associated with the infectivity of betanodaviruses.

Recent studies suggested a possibility of vaccination for controlling VNN or VER. Intramuscular injection of the recombinant RGNNV coat protein, which was expressed in Escherichia coli, induced neutralizing antibodies in the fish Epinephelus septemfasciatus and Chromileptes altivelis, and induced protection against challenge by RGNNV genotype viruses (Tanaka et al. 2001, Yuasa et al. 2002). A similar vaccine efficacy was obtained in juvenile turbot Scophthalmus maximus by intraperitoneal injection of an oil-emulsified recombinant coat protein from SJNNV (Húsgard et al. 2001). The present immunization of kelp grouper with recombinant coat proteins demonstrated that antiRGNNV and anti-BFNNV had cross-neutralizing activity against the heterologous RGNNV and BFNNV, but anti-SJNNV serum and anti-TPNNV serum neutralized only homologous virus (Table 5). This genotype-specific reaction of fish antibodies suggests that a multivalent vaccine will be required to control infection by any genotype. Cross-challenge experiments against fish immunized with recombinant vaccine constructed from different serotypes will be required for the future development of VNN or VER vaccine. 
Acknowledgements. This study was supported in part by a grant from the Japan Sea-Farming Association and by a Grant-in-Aid Scientific Research (B) (14360110) from the Ministry of Education, Culture, Sports, Science and Technology, Japan.

\section{LITERATURE CITED}

Archetti L, Horsfall FL (1950) Persistent antigenic variation of influenza A viruses after incomplete neutralization in vivo with heterologous immune serum. J Exp Med 92:441-462

Bloch B, Gravningen K, Larsen JL (1991) Encephalomyelitis among turbot associated with a picornavirus-like agent. Dis Aquat Org 10:65-70

Chi SC, Lo CF, Kou GH, Chang PS, Peng SE, Chen SN (1997) Mass mortalities associated with viral nervous necrosis (VNN) disease in two species of hatchery-reared grouper, Epinephelus fuscogutatus and E. akaara (Temminck \& Schlegel). J Fish Dis 20:185-193

Curtis PA, Drawbridge M, Iwamoto T, Nakai T, Hedrick RP, Gendron AP (2001) Nodavirus infection of juvenile white seabass cultured in southern California: first record of viral nervous necrosis (VNN) in North America. J Fish Dis 24:263-271

Danayadol Y, Direkbusarakom S, Supamattaya K (1995) Viral nervous necrosis in brownspotted grouper, Epinephelus malabaricus, cultured in Thailand. In: Schariff M, Arthur JR, Subasinghe RP (eds) Diseases in Asian aquaculture II. Fish Health Section, Asian Fisheries Society, Manila, p $227-233$

Emini EA, Hughes JV, Perlow DC, Boger J (1985) Identification of hepatitis A virus-neutralizing antibody by a virusspecific synthetic peptide. J Virol 55:836-839

Felsenstein J (1993) PHYLIP (phylogeny inference package), version 3.573c. Department of Genetics, University of Washington, Seattle

Glazebrook JS, Heasman MP, de Beer SW (1990) Picorna-like viral particles associated with mass mortalities in larval barramundi, Lates calcarifer (Bloch). J Fish Dis 13:245-249

Grotmol S, Totland GK, Thorud K, Hjeltnes BK (1997) Vacuolating encephalopathy and retinopathy associated with a nodavirus-like agent: a probable cause of mass mortality of cultured larval and juvenile Atlantic halibut Hippoglossus hippoglossus. Dis Aquat Org 29:85-97

Hegde A, Teh HC, Lam TJ, Sin YM (2003) Nodavirus infection in freshwater ornamental fish, guppy, Poicelia reticulata-comparative characterization and pathogenicity studies. Arch Virol 148:575-586

Húsgard S, Grotmol S, Hjeltnes BK, Rødseth OM, Biering E (2001) Immune response to a recombinant capsid protein of striped jack nervous necrosis virus (SJNNV) in turbot Scophthalmus maximus and Atlantic halibut Hippoglossus hippoglossus, and evaluation of a vaccine against SJNNV. Dis Aquat Org 45:33-44

Iwamoto T, Mori K, Arimoto M, Nakai T (1999) High permissivity of the fish cell line SSN-1 for piscine nodaviruses. Dis Aquat Org 39:37-47

Iwamoto T, Nakai T, Mori K, Arimoto M, Furusawa I (2000) Cloning of the fish cell line SSN-1 for piscine nodaviruses. Dis Aquat Org 43:81-89

Iwamoto T, Mise K, Mori K, Arimoto M, Nakai T, Okuno T (2001) Establishment of an infectious RNA transcription system for striped jack nervous necrosis virus, the type species of the betanodaviruses. J Gen Virol 82:2653-2662

Editorial responsibility: Jo-Ann Leong,

Kaneohe, Hawaii, USA
Jørgensen PEV (1972) Freund's adjuvants: their influence on the specificity of viral antisera. Acta Pathol Microbiol Scand Section B Microbiol Immunol 80:931-933

Le Breton A, Grisez L, Sweetman J, Ollevier F (1997) Viral nervous necrosis (VNN) associated with mass mortalities in cage-reared sea bass, Dicentrarchus labrax (L.). J Fish Dis 20:145-151

Mori K, Nakai T, Muroga K, Arimoto M, Mushiake K, Furusawa I (1992) Properties of a new virus belonging to Nodaviridae found in larval striped jack (Pseudocaranx dentex) with nervous necrosis. Virology 187:368-371

Munday BL, Nakai T, Nguyen HD (1994) Antigenic relationship of the picorna-like virus of the larval barramundi, Lates calcarifer Bloch to the nodavirus of larval striped jack, Pseudocaranx dentex (Bloch and Schneider). Aust Vet J 71:384

Munday BL, Kwang J, Moody N (2002) Betanodavirus infections of teleost fish: a review. J Fish Dis 25:127-142

Nakai T, Nguyen HD, Nishizawa T, Muroga K, Arimoto M, Ootsuki K (1994) Occurrence of viral nervous necrosis in kelp grouper and tiger puffer. Fish Pathol 29:211-212

Nishizawa T, Mori K, Furuhashi M, Nakai T, Furusawa I, Muroga K (1995) Comparison of the coat protein gene of fish nodaviruses, the causative agents of viral nervous necrosis (VNN) in marine fish. J Gen Virol 76:1563-1569

Nishizawa T, Furuhashi M, Nagai T, Nakai T, Muroga K (1997) Genomic classification of fish nodaviruses by molecular phylogenetic analysis of the coat protein gene. Appl Environ Microbiol 63:1633-1636

Nishizawa T, Takano R, Muroga K (1999) Mapping a neutralizing epitope on the coat protein of striped jack nervous necrosis virus. J Gen Virol 80:3023-3027

Office International des Epizooties (OIE) (2000) Viral encephalopathy and retinopathy. In: Diagnostic manual for aquatic animal diseases. OIE, Paris, p 69-73

Skliris GP, Krondiris JV, Sideris DC, Shinn AP, Starkey WG, Richards RH (2001) Phylogenetic and antigenic characterization of new fish nodavirus isolates from Europe and Asia. Virus Res 75:59-67

Tan C, Huang B, Chang SF, Ngoh GH, Munday B, Chen SC, Kwang J (2001) Determination of the complete nucleotide sequences of RNA1 and RNA2 from greasy grouper (Epinephelus tauvina) nervous necrosis virus, Singapore strain. J Gen Virol 82:647-653

Tanaka S, Mori K, Arimoto M, Iwamoto T, Nakai T (2001) Protective immunity of sevenband grouper, Epinephelus septemfasciatus Thunberg, against experimental viral nervous necrosis. J Fish Dis 25:15-22

Tang L, Lin C, Krishna NK, Yeager M, Schneemann A, Johnson JE (2002) Virus-like particles of a fish nodavirus display a capsid subunit domain organization different from that of insect nodaviruses. J Virol 76:6370-6375

Totland GK, Grotmol S, Morita Y, Nishioka T, Nakai T (1999) Pathogenicity of nodavirus strains from striped jack Pseudocaranx dentex and Atlantic halibut Hippoglossus hippoglossus, studied by waterborne challenge of yolk-sac larvae of both teleost species. Dis Aquat Org 38:169-175

Watanabe K, Yoshimizu M, Ishima M, Kawamata K, Ezura Y (1999) Occurrence of viral nervous necrosis in hatcheryreared barfin flounder. Bull Fac Fish Hokkaido Univ 50: $101-113$

Yuasa K, Koesharyani I, Roza D, Mori K, Katata M, Nakai T (2002) Immune response of humpback grouper, Cromileptes altivelis (Valenciennes) injected with the recombinant coat protein of betanodavirus. J Fish Dis 25:53-56

Submitted: March 12, 2003; Accepted: July 1, 2003

Proofs received from author(s): October 7, 2003 